\title{
La inmanencia subjetiva como flujo virtual de emociones cinestésico-visuales y su potencia constitutiva de realidad
}

\author{
Alejandra Granados \\ Pontificia Universidad Católica del Perú
}

Resumen:

El presente trabajo reflexiona sobre la estructura dual del signo dada por la conjunción del significado, aquello que es objeto de comprensión, y el significante, el medio material que permite expresar lo comprendido. Sin embargo, considerando la vida de emociones despertadas por estímulos cargados de valoración estética, en particular el movimiento corporal y la música, la estabilidad y armonía de dicha estructura dual son puestas en cuestión. En dicho contexto de inestabilidad, la creatividad y la transformación se manifiestan como condiciones esenciales y necesarias para la marcha del lenguaje.

Palabras clave:

(Dis)continuidad, inmanencia, trascendencia, virtualidad, cinestesia.

\begin{abstract}
:
This article considers carefully the dual structure of the sign made up by the conjunction of the meaning, the object of comprehension, and the signifier, the material medium for expressing the aforementioned object of comprehension. However, given the emotional life encouraged by esthetic stimuli, as body movement and music in particular, such stability and consonance of the linguistic dual structure are called into question. In that context of unstableness, creativity and transformation are evinced as essential conditions for language to work.
\end{abstract}

Key words:

(Dis)continuity, immanence, transcendence, virtuality, cenesthesia. 
Que irrumpa la imaginación. Y que pase a segundo plano lo que se tiene en frente. Que irrumpan las imágenes y se apoderen de mis ojos. Porque hay mucho anhelo subsistiendo invisible en el espacio, incendiando el pulso. Porque hay apremio y urgencia, porque el ritmo, porque la melodía.

Y que irrumpa la ceguera con su horizonte nublado. Que manifieste en la pena constante su convicción muda. Aunque duela quebrar el aire, aunque haya un paso punzante tras otro, aferrarse a la disciplina que desaprende la técnica indolente y su ritmo voraz. Y ya no más desenfreno productivo, perspectiva unilateral, postura aplastada. Solo incertidumbre en músculos y articulaciones. En el tiempo que marca este movimiento y este otro, el ahogo será calmo.

Con un nuevo eje, con un nuevo marco. Tornarse tronco y raíz fuertes, ramas y hojas movidas por el viento. Persistir en el movimiento, ser en continuidad con nuevos esquemas. Cómo si no dar cabida a estas emociones que se rebalsan, dónde apoyarse y no perderse, dónde saltar y regresar a salvo, dónde gritar y en realidad ofrecer entonaciones suaves. Reconocerse tensión interminable entre inmanencia y expresión. Reconocerse virtualidad que no descansa y deja trazos, que se esconde y se muestra. Y mientras se pueda, comprometerse a hacer visible lo invisible'

\section{§1. Introducción: la función epistemológico-ontológica del lenguaje}

Dieter Jähnig, historiador alemán del arte, en contra de la lectura del fenómeno estético como práctica desvinculada de la vida cotidiana, objetiva, material y económica, propone en su lugar dos funciones estéticas relacionadas al lenguaje como potencia constitutiva de realidad: el arte como construcción y el arte como figuración actualizante, no reproductiva $(1982,14,16,24)$. La primera función, en tanto paradigmática de la transformación de la vida nómada en sedentaria, consiste en la delimitación del ámbito humano como parte de un universo mayor mediante la edificación de estructuras urbanas y la demarcación territorial en torno a la agricultura, fundamentalmente, y al comercio y la burocratización, como procesos subsecuentes (Jähnig 1982, 14). El arte como construcción confiere a la

1 "Hacer visible lo invisible" es una frase acotada por Stanislavski (2009, 20). 
arquitectura una función creadora y fundacional de visiones del mundo y modos sedentarios de relacionarse con él en tanto vuelve corpóreas coordenadas espacio-temporales rurales y urbanas. Es por eso que los antiguos complejos arquitectónicos son identificados rápidamente como arte, en contraposición a las edificaciones modernas, consideradas meramente como “(...) trozo[s] de realidad" (Jähnig 1982, 11).

La segunda función estética, la figuración actualizante, no se refiere a la modalidad mimética que adoptan la poesía y pintura griegas en el siglo $\checkmark$ a.C. como parte de un giro subjetivo-psicológico generalizado en las disciplinas estéticas de la Grecia clásica (Jähnig 1982, 23). Es decir, el arte como figuración actualizante no consiste en la generación de imágenes con el fin de reflejar o copiar algo previamente dado. Por el contrario, consiste en el despliegue de una facultad creadora de representaciones con las que la humanidad nómada se enfrentó originariamente a la naturaleza (Jähnig 1982, 23, 25). Dicha operación básica, con sus respectivas imágenes actualizadas, instauraría el modo de ser lingüístico en el mundo, es decir, el modo sui géneris del género humano (Jähnig 1982, 26). De acuerdo a dicha interpretación, las pinturas rupestres no serían parte de una práctica mágica con la que hechizar al animal escogido, sino "(...) la actualización efectiva (...) de lo que representaban para esos cazadores el bisonte, el mamut o el ciervo" (Jähnig 1982, 25). El arte como figuración actualizante es identificado como el inicio de una realidad tan concreta como virtual, la realidad del signo actualizada en la vida colectiva de la especie humana.

En esa dirección, la semiótica, a diferencia de las ciencias naturales y aquellas positivas como el derecho y la economía, entiende la realidad humana como cimentada en la semiosis, práctica colectiva constituyente de signos, es decir, de unidades materiales portadoras de significaciones. La estructura interna de dichas unidades, dada por un elemento material (significante) y uno semántico, de carácter virtual en tanto no material, susceptible de ser comprendido e inteligido (significado), es identificada por F. de Saussure al analizar las reglas de formación fonéticas, morfológicas y sintácticas de las lenguas naturales (Courtés 1997, 26). Con la articulación lingüística del continuum físico acústico-sonoro, entonces, se actualiza la posibilidad de formar contenidos semántico-inteligibles y con ello la posibilidad del 
pensamiento y la intelección. Sin embargo, la relación significado-significante no es instanciada únicamente por el signo lingüístico, sino por todo compuesto que cumpla la correlación de materialidad y semanticidad (Courtés 1997, 26). Los gestos y movimientos corporales, las superficies planas de la pintura, la arcilla de la alfarería e incluso los recursos y útiles con los que se desenvuelve toda práctica social, etc., en virtud de su carácter material, pueden también instituirse como soportes movilizadores de significaciones. En ese sentido, el espectro de todo lo que es, de todo lo percibible y expresable, es subsumible al estudio semiótico (Eco 1990, 12). Todos los sistemas de lenguaje, con sus diversos medios significantes entrecruzados en referencias recíprocas, se encuentran inmersos en un campo virtual de significado constituido de múltiples definiciones, asociaciones y relaciones entre signos. El enfoque funcionalista-comunicativo del lenguaje es sobrepasado en la constatación de su función epistemológico-ontológica de producir y reproducir un marco de sentido en el cual la vida humana pueda desenvolverse ${ }^{2}$.

\section{§2. Semiótica y virtualidad}

Sin embargo, la capacidad explicativa del esquema semiótico tiene una falencia. No basta con señalar cada elemento concreto embebido de semanticidad ya que identificar que un determinado significado está enlazado a un significante correspondiente no equivale a entender cómo es posible la unión de una subsistencia material con una inteligible-virtual en una nueva entidad, el signo. El vínculo entre significado y significante es arbitrario, es decir, no se sustenta en ninguna semejanza entre ambos (Saussure 1945, 93-94). Los criterios con los que se analizan y describen las propiedades del espectro sonoro en el que se dan las articulaciones de los signos lingüísticos no dicen nada respecto de los conceptos ni de las ideas que tales signos transmiten. Asimismo, no hay nada en el carácter etéreo o

2 Courtés critica el enfoque funcionalista en relación al esquema emisor/receptor que anula todo contenido semántico que no se encuentre inmerso en una intencionalidad comunicativa precisa $(1997,17)$. Las funciones epistemológicas y ontológicas se mencionan en relación a las modalidades estéticas de la construcción y la figuración actualizante expuestas por Jähnig $(1982,14,16,24)$. 
virtual de los significados que indique su predisposición a colaborar con la materialidad del significante. Es decir, el principio de correlación o solidaridad, aunque manifiesta que todo significado se encuentra asociado a un significante y que ninguna entidad material puede ser un significante sin que le sea asociado algún significado, no explica, sin embargo, el porqué de dicha correlación.

Algirdas J. Greimas señala la misma falencia en el caso de la pintura al negar que esta pueda establecer una relación de carácter icónico (semejanza visual) con aquello que pretende representar $(1994,23)$. El significante planario no tiene las condiciones necesarias para reproducir los rasgos tridimensionales de los objetos tal como se muestran en el mundo físico (Greimas 1994, 22). Los trazos del lápiz y del pincel operan mediante la exclusión de las cualidades no visuales del espacio-tiempo que aparecen a la conciencia cinestésica y a sentidos como el tacto y el oído. Entonces, si la configuración visual de la pintura logra referir al mundo sensible y convertirse en signo es por la intervención de una rejilla de lectura común al emisor y al receptor, construida en el intercambio social (Greimas 1994, 23). Los objetos tridimensionales y las figuras visuales planas son asociadas no por una semejanza esencial entre ambos, sino por acción de dicha rejilla semántica que dictamina similitudes y equivalencias motivada por necesidades epistémicas y ontológicas.

Pareciera que argüir la ausencia de iconicidad (semejanza visual) en favor de una rejilla de lectura tuviera como consecuencia otorgar predominancia al aspecto semántico del signo, es decir, al ámbito inteligible. En el caso del signo lingüístico, si bien es cierto que sin la experiencia del soporte acústico-sonoro no se habría podido articular unidades de sentido, dicho soporte físico no genera sentido por sí mismo. Además, una vez que se ha consolidado el desarrollo de las competencias psíquico-lingüísticas, la automatización de la técnica permite que la concentración radique en la producción y reproducción de significaciones. Pareciera abrirse un campo irresolublemente inconmensurable entre materialidad y virtualidad de no ser por el factum de la cooperación entre dichas modalidades de realidad. Aunque el signo sea una unidad que no disuelve su diferencia interna, sino que la conserva como oposición irreductible, sus dos planos tienen 
en común el carácter diferenciado de sus estructuras formales. Dicho puente, acotado por el desarrollo que hace el lingüista danés L. Hjelmslev del esquema saussureano, muestra con mayor precisión que el poder constitutivo del lenguaje se da tanto desde lo inteligible sobre lo material como desde lo material sobre lo inteligible.

De acuerdo a Hjelmslev, tanto el contenido (significado) como la expresión (significante) presuponen un respectivo medio continuo carente de forma del cual segmentan unidades discretas para luego articularlas según sistemas de reglas correspondientes. El medio continuo es denominado "sustancia"; el sistema de reglas con el que se fragmenta, "forma" (Courtés 1997, 29). En el caso de la expresión, el continuum acústico-auditivo constituye una sustancia divisible de acuerdo a distintos patrones, resultando distintos sistemas de formas, como las escalas de notas musicales y los fonemas que conforman las palabras. En el caso del contenido, nociones generales y abstractas que expresan constantes culturales como la temporalidad, el medio, la muerte, relaciones afectivas, división de roles económicos, etc. tomarían el papel de la sustancia; las diferentes relaciones, aspectos y cualidades semánticas establecidas tomarían el de la forma ${ }^{3}$. Un ejemplo de ello es el contenido general dado por la relación sanguínea-familiar, clasificado y distribuido según concepciones disparejas (Courtés 1997, 34, 35). En húngaro, ser hermana o hermano es expresado con cuatro términos diferentes: batya (hermano mayor), öcs (hermano menor), néne (hermana mayor), bug (hermana menor). En francés, en cambio, es necesario añadir los adjetivos mencionados ya que en las dos formas lingüísticas disponibles solo se hace referencia al género: frère (hermano), soeur (hermana). La ausencia de equivalencias semánticas en la traducción de estos conceptos muestra cómo un espectro semántico indeterminado que es compartido puede ser determinado dentro de múltiples paradigmas conceptuales que no coinciden en sus elaboraciones de sentido.

La aproximación metodológica que representa la oposición entre forma y sustancia tiene como resultado que la estructura interna del signo sea

3 Courtés refiere a la oposición vida/muerte y alegría/tristeza como las posibles articulaciones de "existencia humana", siendo este último término identificado con la sustancia del contenido en el contexto de un cortejo fúnebre en la Francia rural $(1997,47,49,50)$. 
definida como la conjunción de las formas del contenido y de la expresión (Courtés 1997, 37). De ninguna manera, entonces, se debe identificar la noción de forma con el soporte material del significante. Por el contrario, la forma consiste en una segmentación-articulación que alcanza tanto al contenido (significado) como a la expresión (significante). Dentro del esquema de Hjelmslev, entonces, el principio de presuposición recíproca planteado por Saussure se da de modo que a cada forma de la expresión corresponde una forma del contenido, resultando así una relación de isomorfismo o equivalencia entre las estructuras de los dos planos del signo (Courtés $1997,40)$. La pregunta sobre las condiciones que posibilitan la cooperación entre dos subsistencias esencialmente disímiles, la sustancia material de la expresión y la sustancia virtual del contenido inteligible, es aclarada de esa manera. De acuerdo con Courtés, la semiótica y la lingüística pueden investigar la composición del signo y las redes de relaciones entre sistemas de signos solo en tanto se posicionen en el terreno de formas actualizadas. Las sustancias indeterminadas del contenido y la expresión, en cambio, deben ser abordadas por disciplinas con enfoque ontológico como la filosofía y la antropología (Courtés 1997, 37).

Una segunda consecuencia de la propuesta de Hjelmslev consiste en la posibilidad de disociar la correlación formal entre contenido y expresión en aras de un estudio autónomo de cada uno de dichos planos del signo (Courtés 1997, 38). La sustancia segmentada del contenido, esto es, cada posible conjunto de unidades de sentido discretas y articuladas según diferentes relaciones y normas sistematizadas, ha sido estudiada independientemente de su contraparte expresiva por diversos semantistas a finales del siglo XX (Courtés 1997, 39). Lo mismo ocurre en el campo de la expresión con el desarrollo de la fonética, estudio del sonido articulado independientemente de las unidades de sentido (semas) correspondientes. Aunque el alfabeto fonético internacional (API) haya sido desarrollado con anterioridad al trabajo de Hjelmslev, dicha sistematización respalda su apuesta teórica por la posibilidad de la disociación de la estructura interna del signo (Courtés 1997, 36). Tomando en cuenta lo dicho, se puede señalar que, aunque tenga una estructura interna doble y correlacionada, el signo no constituye una síntesis que disuelva su diferencia interna. El hecho de que la oposición se mantenga implica que el signo enmarque dentro de sí 
dos posibles escenarios: uno en el que cada lado (la forma de la expresión y la del contenido) tenga el mismo peso, manteniéndose en una relación de equilibrio, y otro en el que un lado tenga preponderancia sobre el otro. Para ilustrar ambos escenarios, se apelará al contexto de la relación del artista con la técnica estética que practica.

De aplicarse plenamente el principio de correlación o presuposición recíproca entre ambas formas constituyentes del signo, se estaría ante el primer escenario. Tomando como ejemplo la musicalidad instrumental, el primer escenario dictamina que para cada acorde musical y para cada movimiento de arco de violín que lo ejecuta debería haber una unidad de sentido correspondiente. Si lo que se expresa en una determinada melodía es un conjunto de sentimientos de incertidumbre y desesperanza, para cada unidad formal de la expresión debería poder ubicarse un segmento preciso y señalable de uno de estos dos sentimientos. Sin embargo, la división y cuantificación de contenidos inteligibles de cualidad emotiva puede conllevar a la desintegración de su sentido unitario. El segundo escenario contempla, evidentemente, dos posibilidades: una en la que la forma de la expresión predomine, otra en la que lo haga la forma del contenido. La primera posibilidad instancia una relación con la técnica estética mediada por un amplio proceso de interiorización normativa, pero, al mismo tiempo, por un estado de desconocimiento de lo que se quiere expresar. Por el contrario, la segunda posibilidad instancia una relación de desconocimiento respecto de la técnica en cuestión, pero en la que un estado de presencia transparente de la vida de emociones es manifestado en el autoconocimiento y en la seguridad de lo que se quiere comunicar.

El análisis semiótico puede estudiar integralmente al signo, pero también puede decantarse principalmente por la forma del contenido, dejando en segundo plano la forma de la expresión. Sin embargo, aunque admita que la correlación entre ambas formas no es auténticamente plena, decide no concentrarse en la serie de inadecuaciones que aparecen a lo largo del empalme de las extensiones formalmente articuladas de las sustancias del contenido y la expresión. Al soslayar que el signo es una oposición irreductible e inestable se ignora cómo el conflicto entre las formas del contenido y las formas de la expresión es la contraparte no visible de los procesos de 
generación y transformación de fenómenos de sentido. Los procesos de aprendizaje individuales y colectivos ante transformaciones inmanentes de la realidad cultural, emocional y material-económica implican un esfuerzo constante por generar, al mismo tiempo que superar, la disociación interna de las redes de signos que constituyen la realidad mencionada.

Como previamente se ha señalado respecto de la imposibilidad del establecimiento de equivalencias de contenido en la traducción de lenguas, la falta de correspondencias entre las formas de contenido y de expresión también presupone un espacio intermedio carente de estructuras precisas, lo cual da cuenta de la limitación expresiva y semántica de las formas vigentes. En cuanto a la sustancia de la expresión, en tanto independiente de la determinación de lo inteligible, esto es, considerada en sí misma tal cual es, no se puede hablar más que en términos absolutamente negativos. Sin embargo, respecto a la sustancia del contenido, la distinción entre una virtualidad investida de forma y otra carente de esta sugiere una perspectiva de transformación inmanente a la estructura inestable y conflictiva del signo. La virtualidad carente de forma, entendida como dependiente de la articulación doble del signo, y no como fundamento ontológico previo subsistente por sí mismo que se encuentre detrás de la correlación de contenido-expresión, se puede identificar con las inadecuaciones que se muestran en los reacomodos entre las formas de expresión y las formas de contenido. De esa manera, al referir a contenidos inteligibles sin estructuras formales de contenido y expresión precisas que les sean correspondientes, la sustancia del contenido contribuye a pensar la potencia productiva de realidad de lo inteligible en contraste con su función reproductiva.

Para tratar de desarrollar lo que implica postular un medio inteligible carente de formas, conviene apelar a la definición de virtualidad que presenta Pierre Lévy, según la cual lo virtual es aquello que existe en potencia (2007, 33). Partiendo de dicha premisa, Lévy describe la virtualidad como un campo de fuerzas que tiende a la actualización, esto es, a la concreción en alguna forma determinada. Definiendo en términos absolutos la oposición virtualidad-concreción, se puede inferir que lo que es potencialmente, esto es, lo que permanece distinto de su actualización, carece de determinación. Sin embargo, respecto a la sustancia del contenido, las inadecuaciones entre 
las formas de contenido y las de expresión no sugieren un espacio vacío. La ausencia de forma no refiere al no ser absoluto, sino a una indeterminación relativa a los reacomodos de las estructuras actualizadas. En ese sentido, para homologar la virtualidad de Lévy a la sustancia de contenido de Hjelmslev, es importante concebir la potencialidad en términos de movilidad y cambio, no de indeterminación absoluta. Siguiendo dichos términos se obtiene un modelo con el cual pensar las inadecuaciones en las estructuras de signos como procesos de actualización de potencialidades. Los estudios de análisis semiótico y crítica cultural, al abordar el amplio espectro de lo semántico en tanto manifiesto, ya sea como la correlación formal de contenido y expresión o solo desde la forma inmanente del contenido, no deben dejar de lado la potencialidad no articulada del contenido. Recurriendo únicamente a lo actualizado es difícil dar cuenta del poder transformador y constitutivo de realidad del lenguaje y no caer en concepciones que resalten unilateralmente la reproducción de formas previamente dadas.

De acuerdo con lo dicho, se puede intentar una aproximación a la totalidad diversa de la experiencia humana como comprendida en un espectro constituido de dos extremos: uno que refiera a la modalidad concreta y determinada del contenido y la expresión en sinergia, y otro que refiera a la modalidad indeterminada y potencial del contenido que surge en las inadecuaciones ya mencionadas; es decir, entre aquello cuya forma es relativamente sencilla de identificar y explicar, y aquello cuya forma es esquiva o ausente. Si bien el ajuste y desajuste en las estructuras internas del signo y entre sistemas de signos ocurre en cualquier contexto, una manera de hacer que la oposición conflictiva sea claramente manifiesta es enfocarse en el contraste entre lo general o universal y lo concreto o particular. Los juegos de lenguaje que gozan de mayor consenso y generalidad, en tanto instanciados y concretizados en contextos particulares, colectivos-locales o individuales-inmanentes, se identificarían con el extremo de lo determinado. Por el contrario, una relación de disonancia o inconmensurabilidad entre contenidos-expresiones particulares colectivo-locales, por un lado, y generales y abstractos, por el otro, se ubicaría con el extremo de las inadecuaciones indeterminadas. Siguiendo este esquema, la dinámica constitutiva de realidad, esto es, la actualización de potencialidades en 
la generación/resolución de inadecuaciones, acontecería en el marco del conflicto entre lo abstracto y lo concreto.

Debido a que la técnica de cualquier arte tiene como finalidad proporcionar un medio accesible y público que materialice experiencias privadas de subsistencia etérea en tanto no reducibles plenamente a su vehículo neurológico, las vivencias estéticas constituyen un espacio propicio para apreciar los procesos de actualización de lo virtual-potencial. En lo que sigue, se apelará principalmente a la virtualidad emocional involucrada en la práctica de técnicas estéticas performativas que toman el cuerpo como medio expresivo fundamental: el teatro y el baile. Para ello, es fundamental abordar el cuerpo como subsistencia en la que converge la mediación entre aspectos individuales-singulares y generales-universales.

\section{§3. Teatro: el modelo Stanislavski-Hartmann}

En el caso del arte dramático, Stanislavski, director ruso de teatro, se abocó a desarrollar un método de estimulación corporal y psicológica para dar voz a lo que consideraba el motor y fuente de una creación artística genuina: la vida espiritual-inconsciente del personaje/actriz-actor (Hobgood 1973, 152). En El trabajo del actor sobre sí mismo en el proceso creador de la vivencia, Stanislavski señala que la subjetividad consciente del individuo es animada por un trasfondo no accesible desde la intelección consciente $(2007,31)$. El conjunto de emociones y disposiciones psicológicas estructuradas y unificadas alrededor de un eje auto-reflexivo idéntico a sí mismo (identidad individual autoconsciente) encuentra su fundamento en una fuerza natural y orgánica que trasciende la posición individual.

Stanislavski tiene en mente lo inconsciente metafísico, noción del filósofo alemán Eduard von Hartmann basada principalmente en la voluntad schopenhaueriana y en la dialéctica histórica hegeliana (Cantú 2013, 5859). De acuerdo a Hartmann, la totalidad de la realidad, tanto el mundo cultural y social como el natural y material, deviene históricamente gracias al despliegue de una potencia universal física y espiritual que, de manera intencional, legisla sobre ella orientándola hacia un eventual estado de cosas 
ideal en el que se diluyen las diferencias entre lo material y lo espiritual, lo consciente y lo inconsciente (Jensen 2006, 42-43). Dicha potencia intencional legisladora, pensada por Hartmann como la voluntad divina, informa la vida natural al igual que la sociocultural, dotándolas de una inteligencia inconsciente encargada de impulsar a los individuos vivientes a actualizar los fines adecuados a su desarrollo y supervivencia: el inconsciente metafísico, medio universal natural y espiritual en el que cada individuo participa de manera esencial sin necesidad de ser consciente de ello (Jensen 2006, 44). El conglomerado de impulsos e instintos inconscientes propios de la vida psíquica neurológica sería la objetivación del inconsciente en cada individuo animal consciente o no consciente.

La función de la especie humana en este esquema holista material-espiritual es traer al dominio de lo consciente la dinámica inconsciente del desarrollo histórico del mundo natural-cultural, dinámica que se instituye como su condición de posibilidad y fuente última de sentido. Stanislavski hace suyo dicho trasfondo metafísico naturalista para definir como criterio estético fundamental de la acción dramática la actualización de la vida inconsciente en la actualidad presente del cuerpo concreto $(2007,31)$. Sin embargo, hay una diferencia importante entre ambos pensadores respecto de cómo ver el encuentro de lo inconsciente con lo consciente. Hartmann, por su parte, cree leer en la identidad moderna la madurez intelectual para inteligir lo inconsciente desde la racionalidad consciente (Jensen 2006, 44). En otras palabras, lo inconsciente dejaría de ser tal al ser comprendido en categorías conscientes. Stanislavski, en sentido inverso, considera un panorama en el que lo inconsciente predomina y hace retroceder lo consciente. La finalidad de su método consiste precisamente en que la actriz/actor desarrolle las capacidades necesarias para suspender durante la acción dramática la consciencia de sí como individuo particular y convertirse en continente de la fuerza de la naturaleza inconsciente, ya que solo así se logra una acción dramática auténticamente creadora (Stanislavski 2007, 30-31). En tanto trasfondo metafísico de la realidad social y física, la fuerza natural inconsciente infunde organicidad y densidad de contenido no solo al universo del texto dramático, a su secuencia temporal narrativa y a la relación entre personajes, sino también a la relación entre la vida de los personajes con 
la de las actrices/actores que toma lugar en el escenario (Hobgood 1973, 150, 153).

La fuerza natural inconsciente es un medio universal y, en tanto tal, constituye la condición básica para el encuentro entre individuos, sean racionalmente reflexivos o no. En otras palabras, los individuos, como entidades esencialmente relacionales, existen solo en tanto atravesados e inmersos en el mismo espacio ontológico. En ese sentido, al sostener Stanislavski que la técnica psicofísica adecuada puede liberar al individuo de sus condicionamientos conscientes y desatar su vida espiritual interna, no se refiere con esta última a la subjetividad individual consciente, sino a la inmanencia fundida con la trascendencia del inconsciente metafísico (2007, 31). Si bien es cierto que el conjunto de técnicas y ejercicios psicofísicos prescritos es ejecutado bajo la dirección de la voluntad consciente, dicha ejecución está orientada desde un principio a la eventual suspensión de la identidad a la que pertenece dicha voluntad (Stanislavski 2007, 31). Lo que dirige y da unidad al aspecto formal y secuencial de las palabras pronunciadas y los movimientos ejecutados en la acción dramática auténticamente creadora no es la voluntad consciente, sino dicha trascendencia. Un auténtico estado de creación estética, entonces, depende del reconocimiento por parte del individuo artista de su pertenencia a una dimensión colectiva trascendente cuya dinámica interna no es explicable en términos de identidades individuales.

Dejando de lado la lectura naturalista stanislavskiana de la dimensión colectiva que conecta las diferentes inmanencias individuales, lo que se puede rescatar de su concepción estética es la manera en que aborda la dialéctica entre los factores materiales y virtuales. El objetivo de la técnica de una disciplina artística es emanciparse de alguna manera de ella misma, aun siendo condición de posibilidad de las experiencias estéticas. En la gran diversidad de técnicas y géneros de baile, los procesos de aprendizaje tienen en común la condición básica de ejercitar la memoria muscular mediante la imitación y la repetición. Dicho principio, propio de un arte basado en el movimiento, no consiste únicamente en un medio enfocado en la realización de la forma estilística ideal por sí misma, sino también como vehículo de expresión en aras de una interpretación rica en contenido. 
Solo mediante la automatización de la técnica, la atención cognitiva puede desviarse al despliegue de la vivencia emocional-afectiva.

\section{§4. Baile: temporalidad continua-discontinua. Imaginación y metáfora}

Considerando su existencia orgánica, el cuerpo humano comparte con la animalidad carente de consciencia la vida de la plena inmediatez, un modo de estar sin contraste ni distanciamiento respecto del medio habitado. En De la utilidad y los inconvenientes de la historia para la vida, Nietzsche define dicha modalidad de existencia como un modo de estar en el presente sin dividirlo ni en pasado ni en futuro $(O C 1,697)$. Al no haber nada que deje de estar presente, se imposibilita que algo sea recordado en tanto ausente y que surja la consciencia como memoria. En tales condiciones de ininteligibilidad, la realidad natural puede ser postulada hipotéticamente como una extensión indistinta en un presente eterno, un continuum similar a la sustancia de la expresión en tanto materialidad desde el punto de vista de la materialidad. De la misma manera, el cuerpo humano en tanto orgánico se diluye más que se diferencia del entorno físico ${ }^{4}$. Sus funciones vitales, tales como el metabolismo celular, la circulación cardiovascular, etc., son controladas desde el sistema nervioso parasimpático, esto es, sin intervención de la consciencia.

Sin embargo, considerando los procesos físicos de cambio, cíclicos en términos meteorológicos, dinámicos a nivel de la interacción entre entidades animadas e inanimadas, y a nivel atómico en el funcionamiento interno de cada organismo corporal, la realidad natural está mediada por el movimiento, el tránsito y la transformación. Las coordenadas del presente eterno y la extensión indiferenciada propias del espacio-tiempo de la plena inmediatez-inmanencia deben ser matizadas con el componente dinámico del cambio. La extensión indiferenciada se convierte en escenario de una sucesión de instantes por lo que sería más conveniente referirse a la

4 Nietzsche habla de cómo la especie humana en términos fisiológicos tiene en común con "la vida entera" el no necesitar de un espejo para existir y desenvolverse $(O C 3,868)$. 
realidad natural como un flujo indistinto 5 . La entidad animada carente de consciencia continúa sin extrañarse de su medio ni de sí misma, y continúa fundiéndose en la inmanencia, pero desde la temporalidad. No hay consciencia inteligible de esta última y en ese sentido se está en un instante eterno, pero desde la corporalidad la temporalidad es inmanente. El cuerpo orgánico continúa perdiéndose en la inmediatez debido a la imposibilidad de establecer diferencias inteligibles. La única autoafirmación posible es la conservación de la especie que no requiere de la afirmación del individuo como entidad única y singular, sino únicamente como individuo genérico ${ }^{6}$.

Sin embargo, a diferencia de la animalidad no consciente, el cuerpo humano niega la unilateralidad de su individualidad indiferenciada-genérica y se distingue de su medio mediante una acción de auto-referencialidad ${ }^{7}$. El cuerpo que vivía sumergido en su animalidad inmanente sin que mediase ningún hito con el cual diferenciarse de sí y de otros, se vuelve extraño a sí mismo al ser mediado por su reflexividad (Cimatti 2016, 149-150). Para que ello ocurra, sin embargo, según la teoría de la autoconsciencia en la Fenomenología de Hegel, cada sí mismo se vuelve consciente de sí solo mediante el reconocimiento de otro (Hegel 2018, § 178). Es en un contexto de referencias bidireccionales, en el que cada individuo es pensado por otro como siendo de una determinada manera, que un cuerpo viviente puede romper la plena inmediatez y reconocerse como siendo diferenciadamente (Brandom 2019, 247, 256, 257). Los múltiples actos individuales de auto-referencialidad, entonces, presuponen la simultaneidad de los múltiples actos de salir de sí y referir al otro, arribando eventualmente a la determinación de una propiedad común: la capacidad de ser autoconsciente mediante el

5 Se hace referencia a la definición de realidad natural que aparece en el aforismo 112 de La ciencia jovial: un continuum, un fluir indiferenciado (Franco 2011, 130). La sustancia de la expresión puede identificarse como dicho continuum.

6 Analizando las propiedades que definen al idealismo hegeliano, Pinkard discute sobre lo que diferencia a la especie humana de los animales no conscientes $(2017,7,9)$. Respecto de ello, señala que las especies animales que no necesitan entablar una auto-relación individual para relacionarse con su medio, sino únicamente ser empujadas por las necesidades de su especie, requieren la supervivencia del individuo solo como medio para el fin de la reproducción de la especie.

7 En la dialéctica hegeliana de la autoconsciencia, la negación del ser-en-sí inmediato e indiferenciado se transforma en la modalidad mediada y reflexiva del ser-para-sí, pero con la necesaria mediación del ser-para-otro (Hegel 2018, § 178). 
reconocimiento del otro (Honneth 2008, 89). De acuerdo a lo dicho, el cuerpo humano se constituye como tal al desarrollar la capacidad intelectiva de establecer diferencias y de superarlas: es consciente de sí como individuo único dentro de un mismo género ${ }^{8}$.

El cuerpo mediado por la reflexividad individual-colectiva supera la preeminencia del presente trayendo a la consciencia la transitoriedad de su inmanencia corpórea. Sin embargo, para que la consciencia pueda pensar la sucesión ininterrumpida e indiferenciada del continuum, aísla segmentos de esta y los cristaliza en un formato temporal marcado por límites, estructuras y formas. Los instantes que se diluían en el presente continuo y dinámico se vuelven entidades discretas en la inauguración de un plano trascendente en tanto ontológicamente distinto a la materialidad indiferenciada: el plano del lenguaje como sistema de signos (Krebs 2013, 32). La temporalidad trascendente, entonces, detiene el flujo de la inmediatez, pero no implica un retorno a la presencia inmóvil del cuerpo absorto y no reflexivo puesto que se fundamenta en la diferenciación de la forma. Consiste más bien en un espacio virtual y etéreo, "un mundo propio" que surge de aplicar a la vida de la plena inmediatez, ya sea en la modalidad dinámica o inmóvil, un corte originario con el poder de subvertir la inmanencia en trascendencia, de informar donde no cabía forma inteligible alguna ${ }^{9}$. Es por eso que, citando a Jonathan Swift, Krebs describe el poder del lenguaje como una acción subversiva de la realidad, transformando la inmediatez en virtualidad mediada, lo inasible en fantasmas duraderos (Krebs 2013, 32).

El cuerpo humano, distanciado irreversiblemente de la inmanencia animal absolutamente indiferenciada, pero que conserva su carácter orgánico, pasa a desenvolverse en demarcaciones espaciotemporales que superponen inmediatez física y trascendencia virtual. Esta inmediatez superpuesta, sin embargo, no puede considerarse en términos absolutos como completamente ajena a las determinaciones formales del lenguaje. Conviene,

8 La capacidad de establecer y superar diferencias es desarrollada por Hegel en los parágrafos 163 y 177 de la Fenomenología mediante el concepto de infinitud que refiere a la conservación de la identidad en lo distinto de sí (Siep 2014, 86, 89, 90).

9 En el aforismo 11 de Humano, demasiado humano, Nietzsche concibe a la conciencia humana como artífice del corte originario mencionado (Cimatti 2016, 155). 
por el contrario, enfocarla desde los espacios vacíos que trastornan el isomorfismo de las articulaciones ensambladas del contenido y la expresión, esto es, desde la virtualidad sin forma que subsiste en las inadecuaciones entre las formas de contenido y expresión. El principal supuesto en que se basa el presente trabajo es que el cuerpo es el medio por excelencia en el que se superpone la mediación y la inmediatez: por un lado, la consciencia extrañada de la animalidad inmanente pero unificada en la inteligibilidad trascendente de la identidad consigo mismo y, por el otro, la temporalidad orgánica inmanente que lo conecta inconscientemente con su medio. La continuidad de instantes permanece en la sensación corporal del espacio, en los elementos físicos que yacen en él y en las funciones vitales no conscientes, a la par que la reflexividad del cuerpo mediado divide, cristaliza y sistematiza socialmente lo percibido de sí mismo y de lo distinto de sí con formas inteligibles y expresivas.

Siguiendo el hilo de lo expuesto, el análisis del movimiento estético debe ser enmarcado en un modo de concebir la inmanencia del sujeto consciente (en particular, la vida emocional del individuo), así como constituida en la tensión entre lo continuo y lo discontinuo, lo abstracto y lo concreto, lo genérico y lo particular, lo distinto de sí y lo común ${ }^{10}$. Una asunción básica en dicho análisis es que, así como los movimientos corporales estéticos tienen como trasfondo la emocionalidad inmanente, esta es retroalimentada y enriquecida exponencialmente por la ejecución de dichos movimientos y por los estímulos cinestésicos que generan. Debido a ello, desde el punto de vista semiótico, se sigue sin dificultades que las emociones experimentadas y transmitidas al público, por un lado, y los movimientos organizados en patrones espacio-temporales estéticos, por el otro, constituyen un ensamble significante de formas de contenido y expresión.

Sin embargo, retomando el hecho de que las artes performativas, al tomar el cuerpo como medio fundamental, tienen la particularidad de hacer evidente la dialéctica entre lo inmanente y lo trascendente, lo abstracto y lo concreto, se debe considerar a qué implicancias conlleva que los

10 Es importante recordar que lo continuo se identifica con las sustancias de contenido y expresión, y que lo discontinuo con la articulación formas de dichas sustancias (Courtés 1997, 29). 
movimientos corporales y las emociones estético-cinestésicas sean articuladas en el presente continuo e inmediato, esto es, en la sucesión espacio-temporal de instantes ${ }^{11}$. La/el artista, al momento de ejecutar la técnica estética discontinua y concreta en un espacio-tiempo continuo e inmediato, lleva consigo las condiciones psicológicas y sociales que constituyen su identidad individual-colectiva. Ello significa una colisión entre factores concretos-trascendentes como la técnica estética en cuestión, los patrones rítmicos y melódicos involucrados, y los sistemas de signos verbales que teorizan y buscan dar sentido a la cooperación de los dos anteriores, factores inmanentes-trascendentes como las condiciones psicológicas y sociales mencionadas, y factores de inmediatez como la sucesión de instantes y las sensaciones corporales de continuidad con el entorno físico.

Sin embargo, aunque los factores discontinuos-concretos-trascendentes y los continuos-abstractos-inmanentes se influyan mutuamente en el presente continuo, los primeros retroceden ante el protagonismo de los segundos. Dicha afirmación se puede corroborar examinando el nivel de realización de la intención expresiva verbal de dar cuenta del sentido de las emociones cinestésicas una vez que ha cesado el movimiento: no puede reproducir unidades discretas de contenido a las cuales empatar unidades discretas de expresión resultantes de la segmentación del movimiento corporal. Esto se debe a que, en el lapso de tiempo en que los movimientos se empalman con cada segundo transcurrido, la autoconsciencia individual (o el cuerpo-psique autoconsciente de su inmersión dinámica en el presente progresivo) no se detiene a pensar en unidades discretas, sino que concibe el flujo de emociones como totalidad abierta indeterminada con límites y estructuras internas difusas. Entonces, cada vez que el cuerpo humano inicia una secuencia de movimientos estéticos, las formas explícitas de todo el conocimiento cultural aprendido, y el aparente isomorfismo estático del contenido y la expresión, se diluyen en un trasfondo indeterminado. La interrelación de las formas de contenido y expresión de los signos disponibles es atravesada por intervalos, si bien no excesivamente distantes, sí inconmensurables en tanto no encajables. En tales condiciones, la función

11 El presente continuo, entendido como la sucesión de instantes, se identifica con la sustancia de la expresión. 
constitutiva de realidad del lenguaje tiene predominancia sobre la función reproductiva. Mientras que esta última solo repite mecánicamente formas previamente dadas, la primera aprovecha las inadecuaciones para reformular correlaciones y actualizar potencialidades.

La inmanencia subjetiva sumergida en la sucesión de instantes mediante el movimiento corporal se identifica plenamente con las sustancias del contenido y la expresión. La totalidad abierta que constituye el flujo de emociones cinestésicas se abre paso entre las inadecuaciones de las formas de contenido y expresión, y motiva reestructuraciones a lo largo de sus articulaciones. Los signos lingüísticos que pretendan reemplazar a la forma corporal de expresión para determinar verbalmente los contenidos cinestésicos no pueden ser utilizados de modo que solo repliquen formas verbales convencionales, sino de modo que predomine la innovación semántica ${ }^{12}$. Respecto de dicha finalidad, el lenguaje descriptivo estructurado en términos positivos-referenciales no es competente. Por el contrario, es a través del lenguaje poético que se complementa la acción creativa de la inmanencia subjetiva en el formato de emociones cinestésicas.

De acuerdo con Ricoeur, el lenguaje poético se compone principalmente de metáforas, estrategia lingüística que genera nuevos contenidos en la asociación de planos semánticos disímiles, transformando en pertinencia predicativa lo que a nivel literal es impertinente (Geniusas 2015, 231-232). Para lograr dicha transformación, el uso metafórico del lenguaje necesita recurrir a imágenes que no resulten de la imitación de realidades perceptuales, sino del entendimiento disonante de algo como algo distinto de lo que es (Geniusas 2015, 233). La imaginación de la que se vale el uso metafórico del lenguaje, entonces, no es de carácter reproductivo, sino productivo: cuestiona la actualidad de la realidad generando entidades inteligibles estrictamente virtuales, sostenidas únicamente en un soporte neurológico e inexistentes en el plano empírico. En suma, se trata de ficciones en tanto que ponen entre paréntesis la validez de cómo son en realidad las cosas, afirmando que son precisamente lo que no son en realidad

12 En el trabajo de Ricoeur, la innovación semántica será entendida en el marco del uso metafórico del lenguaje (Geniusas 2015, 231-232). 
(Geniusas 2015, 229-230). Es en virtud de dicha operación que, a pesar de que sus contenidos reniegan del valor de verdad empírico referencial, tienen la capacidad de generar cambios concretos en los estados de cosas existentes en dicha actualidad empírica, introduciendo en el imaginario colectivo nuevas posibilidades, ideas y valores (Geniusas 2015, 233). La imaginación productiva, entonces, se acomoda perfectamente a lo que el lenguaje metafórico necesita: generación de sentidos para restablecer la pertinencia predicativa en los planos semánticos disímiles que han sido asociados impertinentemente.

Gracias a la imaginación productiva, el lenguaje metafórico puede dar voz a las inadecuaciones abiertas por las emociones cinestésicas experimentadas en la inmersión corpórea y dinámica en el presente continuo. Geniusas, a diferencia de Ricoeur, no considera que las ficciones de la imaginación productiva sean antecedidas por formulaciones verbales arbitrarias de modo que aquellas sean relegadas a un rol subsidiario, supeditado a una supuesta actividad lingüística principal (2015, 234-235). La innovación semántica proviene de la virtualidad sin forma propia de la inmanencia subjetiva, de las entidades virtuales ficticias pensadas, en este caso, desde las emociones cinestésicas. Estas son principalmente inteligibles, no en un sentido racionalista, sino en tanto que no son reducibles a sus soportes neurológicos y bioquímicos. $Y$ aunque dependan de la forma expresiva de los movimientos corporales, en tanto que solo inmersas en la sucesión de instantes cobran existencia virtual, esta virtualidad no se agota en los aspectos materiales, sino que su cualidad ontológica esencial definitoria se ubica en el plano de la sustancia del contenido. Respecto al factum de la cooperación entre dos sustancias disímiles, la sustancia virtual del contenido y la sustancia material de la expresión, aunque sea evidente y necesaria, el porqué continúa siendo un misterio. 


\section{Bibliografía}

Brandom, Robert, 2019. A Spirit of Trust. Cambridge and Massachusetts: The Belknap Press of Harvard University Press.

Cantú, Mario, 2013. Von Hartmann vs. Freud: lo inconsciente en Stanislavski. Telón de fondo. Revista de teoría y crítica teatral 18, 55-78.

Cimatti, Felice, 2016. “Felicidad de grillo, alegría de grillo". Lenguaje y animalidad humana en Nietzsche. Instantes y azares. Escrituras nietzscheanas 17-18, 153-174.

Courtés, Joseph, 1997. Análisis semiótico del discurso. Madrid: Gredos.

Eco, Umberto, 1990. Semiótica y filosofía del lenguaje. Barcelona: Lumen.

Franco, Paul, 2011. Nietzsche's Enlightenment. The Free-Spirit Trilogy of the Middle Period. Chicago and London: The University of Chicago Press.

Geniusas, Saulius, 2015. Between Phenomenology and Hermeneutics: Paul Ricoeur's Philosophy of Imagination. Human Studies 38 (2), 223-241.

Greimas, Algirdas, 1994. Semiótica figurativa y semiótica plástica. En: Figuras y estrategias. En torno a una semiótica de lo visual, ed. Gabriel Hernández. México D. F.: Siglo XXI, 17-42.

Hegel, G.W.F., 2018. The Phenomenology of Spirit. Traducción de Terry Pinkard. Cambridge: Cambridge University Press.

Hobgood, Burnet, 1973. Central Conceptions in Stanislavski's System. Educational Theatre Journal 25 (2), 147-159.

Honneth, Axel, 2008. From Desire to Recognition: Hegel's Account of Human Sociality. En: Hegel's Phenomenology of Spirit. A Critical Guide, eds. Dean Moyar y Michael Quante. Cambridge, New York: Cambridge University Press, 76-90.

Jähnig, Dieter, 1982. Historia del mundo, historia del arte. México D.F.: Fondo de Cultura Económica.

Jensen, Anthony, 2006. The Rogue of All Rogues: Nietzsche's Presentation of Eduard von Hartmann's Philosophie des Unbewussten and Hartmann's Response to Nietzsche. Journal of Nietzsche Studies 32, 41-61.

Krebs, Victor, 2013. The Power of Ghosts. Jung Journal: Culture and Psyche 7 (4), 31-38.

Lévy, Pierre, 2007. Cibercultura, informe al consejo de Europa. México D.F.: Anthropos.

Nietzsche, Friedrich, 2011-2016. Obras completas, ed. Diego Sánchez Meca. Madrid: Tecnos. 4 volúmenes $(O C)$.

- UPH, I, 2011, Diego Sánchez Meca, Tecnos.

- HH, III, 2014, Diego Sánchez Meca, Tecnos.

- GC, III, 2014, Diego Sánchez Meca, Tecnos. 
Pinkard, Terry, 2017. Does History Make Sense? Cambridge and London: Harvard University Press.

Saussure, Ferdinand de, 1945. Curso de lingüística general. Buenos Aires: Losada.

Stanislavski, Konstantín

- 2007. El trabajo del actor sobre sí mismo en el proceso creador de la vivencia. Barcelona: Alba.

- 2009. El trabajo del actor sobre sí mismo en el proceso creador de la encarnación. Barcelona: Alba.

Siep, Ludwig, 2014. Hegel's Phenomenology of Spirit. Cambridge and New York: Cambridge University Press. 